\title{
BNWL-SA: 4590
}

RADIOLOGICAL INSTRUMENTATION PREPAREDNESS FOR EMERGENCIES

CARL M. UNRU'H

BATTELLE-NORTHWEST

Richland, Washington

1. INTRODUCTION

Anyone responsible for action at the time of a radiation accident should anticipate such an event. While careful facility design and conservative operating procedure can be effective in preventing and minimizing any accidents involving radioactive material, we should all be good boy scouts and "Be prepared." Consider the following:

1) We do not plan to have an accident.

2) We do plan to have an accident emergency plan.

3) Planning for emergency action prior to an accident is a unique opportunity.

Surely we can be agreed that it is better to plan before needed than after needed. OK----What are the elements of getting an effective Radiological Instrument Preparedness Plan for Emergencies into place?

One should carefully consider the requirements of one's radiological instrumentation preparedness program before selecting instrumentation. The program requirements and the instrumentation performance capabilities should determine the type of instrumentation to be selected and used. Proper instrumentation selection can lead to simplified radiation measurements and ease in interpretation of results. The temptation to purchase MISTRBBUION BF THIS DOCUMENT IS UNLHAITEO 


\section{DISCLAIMER}

This report was prepared as an account of work sponsored by an agency of the United States Government. Neither the United States Government nor any agency Thereof, nor any of their employees, makes any warranty, express or implied, or assumes any legal liability or responsibility for the accuracy, completeness, or usefulness of any information, apparatus, product, or process disclosed, or represents that its use would not infringe privately owned rights. Reference herein to any specific commercial product, process, or service by trade name, trademark, manufacturer, or otherwise does not necessarily constitute or imply its endorsement, recommendation, or favoring by the United States Government or any agency thereof. The views and opinions of authors expressed herein do not necessarily state or reflect those of the United States Government or any agency thereof. 


\section{DISCLAIMER}

Portions of this document may be illegible in electronic image products. Images are produced from the best available original document. 
and to use novel or highly sophisticated instrumentation should be resisted unless such instrumentation is actually needed and can be used beneficially.

In the selection of any emergency instrumentation, the intended use, the required performance of the instrumentation and the skill of the personnel utilizing the instrumentation will play an important role in determining the quality and cost of the instrumentation to be used.

To establish, the type of instrumentation to be used and the parameters of its use and interpretation, four factors should be considered: need, selection, calibration, and interpretation.

The need for specific instrumentation and dosimeters is: established by the types of radiation that may be encountered and the qualifications of the staff who will be utilizing the instrumentation. The selection of appropriate radiation monitoring and dosimetry instrumentation requires a review of the instrument performance factors actually needed and an analysis of the ad"vantages nf each instrument." One should carefully compare- the proposed instrumentation against the actual needs and select instrumentation that will do the job required.

The calibration of radiation monitoring and dosimetry instrumentation plays a primary role in assuring that radiation measurements are meaningful. Standardized radiation sources, secondary radiation standards, and calibration procedures need to be established to assure the desired accuracy for all'instrument applications. 
The interpretation of emergency instrumentation readings is required to provide meaningful emergency evaluation data. Instruments designed for ease of use and interpretation will greatly simplify the complexities of the program and may permit administration of part of the radiation protection program with a semi-technical staff. 
2. DETERMINATION OF NEEDS FOR RADIOLOGICAL INSTRUMENTATION

The types of radiation and the radionuclides that might be encountered will help determine instrumentation needed. If only tracer quantities of radioactive material will be involved, then only radiation detection type equipment will be required for emergency response. If any appreciable quantities of radionuclides will be involved, then a full complement of emergency instrumentation should be available.

The types of instrument required will be determined also from the types of radiation that may be encountered. For example, if only gamma and beta emitters will be encountered, there would be no need for alpha or neutron monitoring instrumentation. In evaluating instrumentation needs, one may consider the following radiation categories that define the instrumentation types that may be required.

1) Photon radiation: The energy range and dose range that might be encountered in working with gamma radioactive sources or. photon qenerating equipment should be determined. Most large nuclear facilities anticipate photon radiation in the energy range from a few tens of $\mathrm{KeV}$ to a few $\mathrm{MeV}$. Dose rates may range from tenths of mrad per hour to hundreds and thousands of rad per hour.

2) Beta radiation: Beta radiation sources, such as strontium-90, natural uranium, sulphur-35 and tritium, may require different monitoring approaches than mixed fission product radionuclides where a full range of beta energies may be encountered. 
Beta radiations of energies below $0.25 \mathrm{MeV}$ will require thinwalled counters for detection. Beta radiation with energies above $3 \mathrm{MeV}$ may require special monitoring equipment to differentitate them from gamma and other photon radiations. The relatively short range of beta particles in air and their limited penetrating power may lead to special instrument design features and dosimetry interpretation methods if good radiation measurement and dosimetry are to be attained, particularly for sulphur-35, tritium and promethium-147. For major releases, air sampling and counting equipment should be available.

3.) Alpha radiation: Most alpha radiation to be encountered will originate from the transuranic radionuclides. The alpha particle energies will be a few $\mathrm{MeV}$. Since alpha radiation is not an external dose problem, only detection type equipment will be required for monitoring with respect to its external impact. For major releases, air sampling and counting equipment should be available.

4) Neutron radiation: Neutron radiation may originate from neutron sources, neutron generators, particle accelerators and nuclear reactors. Monitoring and dosimetry techniques for neutron radiation are moderately well developed, but improvements for monitoring in the energy range from thermal to a few hundred $\mathrm{KeV}$ are needed. If neutrons could be present, then neutron monitoring instruments should be provided.

5) High-energy proton radiation: In the vicinity of accelcrators and similar high-energy particle generating equipment, 
photon radiation with energies in the tens, hundreds and perhaps thousands of MeV may be encountered. Measurement techniques and dosimetry methods for these energy ranges are not well defined and will require special consideration and the use of special monitoring and dosimetry instrumentation by qualified health physicists. One would anticipate that such generating .equipment would not be shut down in the course of the accident and monitoring requirements appear to disappear.

6) High-energy particle radiation: High-energy accelerators will require special monitoring capabilities. The high-energy particles may range from electrons, protons, deuterons, alphas and light-weight atomic nuclei to the very high-energy meson type particles. The radiation monitoring and dosimetry technology for many of these radiations is not well defined and will require special consideration and special study. Again, monitoring in these high-energy ranges would appear to be unnecessary for anticipated accidents.

7) High dose photon radiation: An accident may lead to abnormally high photon radiation dose rates and dnses. A few instruments and dosimeters to measure high dose rates and high doses, which may range from a few hundred to a few thousand rad per hnitr or rads should be available and calibrated for use. under emergency conditions.

\section{Staff capabilities}

The type of instrumentation needed and its complexity will also be determined by the level of training and the size of the staff providing services. 


\section{Performance criteria}

In determining the needs for equipment, one should review in detail each of the design or performance criteria shown in Table 1. The use of these criteria in the selection and evaluation of emergency instrumentation is an important part of the methods of measurement and interpretation of results in radiation emergency analysis. 
TABLE I. RADIATION EMERGENCY INSTRUMENTATION

DESIGN AND PERFORMANCE CRITERIA

I. Mechanical

A. General Construction

1. Structural strength

2. Component layout

3. Moisture and water resistance

B. Human engineering

1. Safety features

2. Ease of handling

3. Ease of servicing.

II. Electrical

A. Power supply

1. Stability

2. Battery life

B. Transient effects

C. Switching transients

D. Capacitance and RF effects

E. Temperature dependence

F. Noise and vibration effects

G. Geotropic effects

H. Extracameral radiation response

I. Iinearity

J. Response Time

K. Dependability

III. Raه1ological

A. Detection limit

B. Range

C. Sensitivity

D. Accuracy

E. Reproducibility

F. Saturation

G. Input voltage dependence

H. Energä dependence

I. Temperature dependence

J. Pressure dependence

K. Angular dependence

L. Stability - drift

M. Response to unwanted radiation 


\section{SELECTION OF INSTRUMENTATION}

The selection of the proper instrumentation for an emergency program is critical in the establishment of an adequate, wellbalanced program. $\lambda$ wide range of radiation instruments is commercially available, and many special purpose instruments can be made to meet particular needs. The types of instrumentation generally available and the criteria to consider in their selection are reviewed in this section.

\subsection{Dose-rate monitoring}

\subsubsection{Photon radiation monitoring}

For photon dose-rate monitoring, ionization chamber, scintillation crystal and shielded GM tube type instruments will usually meet the basic requirements. A suitable instrument should be light in weight, portable, and dependable. The accuracies required for most emergency situations will not demand the sophisticated instrument design and readout that is commonly associated with precision radiation measurements.

The dose-rate ranges of interest may be from about one mrad/h to a few rad/h for most situations; however, instrumentation capable of monitoring dose rates of a few hundred rad/min should be available for use in extreme emergencies. Ionization chambered instruments can be constructed with nearly tissue-equivalent walls, and, hence, with energy responses closely paralleling those observed in biological tissues. 
Scintillation counters can also be used for photon doserate measurements. The scintillation detectors are generally not as tissue equivalent as the ionization chamber instruments, and, hence, a correction for energy response or provision of a radiation detector shield system to linearize instrument energy response may be required.

Specially designed shield can give GM detector type instruments energy response characteristics acceptable for emergency dose rate monitoring. Such instruments should be specially tested to assure they do not "swamp out" and read too low in very high intensity radiation fields.

\subsubsection{Beta radiation monitoring}

The Geiger-Muller counters have provided dependable and useful beta detection monitoring. New technologies have permitted the manufacture of a very thin-walled beta detector tubes - 20-40 $\mathrm{mg} / \mathrm{cm}^{2}$ aluminum walls to $1-2 \mathrm{mg} / \mathrm{cm}^{2} \mathrm{mica}$ end-windowed tubes. For the relatively high-energy beta emitters above $0.25 \mathrm{MeV}$, metal wall tubes are commonly used for beta activity measurement. For the lowenergy beta emitters, such as sulphur-35 and carbon-14, mica windowed counters are commonly used. For the ultra-low energy beta emitters, such as tritium, windowless counters are required.

For beta dose-rate monitoring, the air ionization chambers seem to provide the best approach. A carefully designed chamber with a thin entrance window is required. Shallow chambers or chambers with large diameter-to-depth ratios are recommended so that geometry corrections may be minimized. It should be stressed that ionization chamber instruments are best used for dose-rate 
monitoring, while the GM tube type instruments may be used for detection and for determination of the quantity of radioactive material present. Special shielding may be used with GM tubes to give fair dose rate measurement accuracies over a reasonable energy spectrum.

Solid-state diode materials and scintillation crystals for beta detection may be applicable in special situations. Particularly, the small diode detectors may be used to probe generally inaccessible locations, and the scintillation counters may be used for simultaneous detection and separation of beta radiation in the prosence of photon radiation.

\subsubsection{Neutron radiation monitoring}

It seems unlikely that neutron monitoring will be required in the general environment--yet loss of control of a neutron source can lead to the need. The best available neutron dose-rate monitoring instruments are based on the use of moderators to yield thermal neutrons for detection. $\mathrm{BF}_{3}$ gas-filled tubes or thermalneutron sensitive scintillation crystals are used as the detectors. Several systems have bcon devised in dil attempt to obtain a detector response that can be directly related to neutron dose over all neutron energies. This objective has proven to be a most difficult task but has met with moderate degrees of success. The most used neutron dosimetry systems are (1) the double moderator, (2) the multi-sphere, and (3) the Andersson rem counter. In the double moderation concept one selects a spherical moderator of such dimensions that it produces the desired response over a wide energy range and uses a smaller spherical detector to determine if the energy is, in fact, within the appropriate response range of the instrument. 
By utilizing the ratio of readings with the large and small moderators, the ability to apply some energy correction factors is attained. The accuracy of this system is adequate for many monitoring requirements. It encounters difficulty when a large fraction of the total neutron dose results from neutrons with energies between a few $\mathrm{eV}$ and a few hundred KeV.

The multi-sphere concept consists of a set of spherical. moderators ranging from 2 in. to 12 in. in diameter. By recording the thermal-neutron detector count rates when the detector is surrounded by each of these moderators, and by processing this data with a computer program, information may be obtained by relating to neutron spectrum and the dose rate. Generally this concept is too complex to be recommended for emergency neutron dose rate monitoring.

The Andersson rem counter is similar to the double moderator system in size, shape and operating principles. It attains its good response characteristics by having a boron absorber placed within the moderator to correct for the over-response of the system when exposed to neutrons in the $0.025 \mathrm{eV}$ to $100-\mathrm{KeV}$ range. It is a good emergonoy instrument.

Although other neutron measurement systems are available, the simple double-moderator concept or the Andersson rem meter will meet most radiation monitoring requirements.

Considerable progress has been made in producing a practical tissue-equivalent neutron detector system. By utilizing appropriate tissue-equivalent chambers, it is possible to separate the gamma dose-rate componont from the neulroil duse-rate component and to measure radiation doses from both of these radiations independently. 
Although the principles of tissue-equivalent chamber design, operation and interpretation are well established, the reduction of this system to a pracicical field monitoring instrument has not yet been fully successful.

\subsubsection{High-dose photon monitoring}

For monitoring radiation fields, measuring tens and hundreds of rad/hr, special instrumentation is usually reguired. These instruments should be designed to assure reliability and dependable performance on an infrequent application schedule. They should be calibrated over the full range of their response and should be designed with chambers sensitive only to photon radiation. Most instrumentation of this type will be used for special studies or for emergency re-entry and rescue activity after a radiation accident. It would be most unfortunate to curtail a rescue activity or to decide a lifesaving entry to be impossible due to a misinterpretation of beta radiation as penetrating radiation dose. Chambers with wall thicknesses of at least $3 \mathrm{~mm}$ aluminium equivalent are recommended to avoid confusing lower-energy beta radiations with photon radiations when usjing these instrumente.

\subsubsection{High-energy particle monitoring}

High-energy particle dose-rate monitoring is a complex subject. First, it is ditticult to design and calibrate instrumentation for use at high energies, and second, there is a limited biological data to translate energy deposition measurements into radiation dose measurements. The use of tissue-equivalent chambers seems to be an obvious and preferred method for many high-energy dosimetry measurements. The use of particle detectors and spectrometers to 
identify particle energies will permit the collection of data. which may be used to calculate dose rates. The use of! scintillation counters with various crystal depths provides another method of estimating particle energy and linear energy transfer values.

\subsection{Personnel dosimeters}

3.2.1. Beta-gamma dosimeters

(a) Film dosimeters

Film dosimeters provide a convenient, dependable, and, if properly handled and calibrated, accurate dosimetry system for personnel dose evaluation. Their capabilities and performance features are well documented in many publications. One should not choose to abandon the use of film dosimeters or select other types of personnel dosimetry without careful consideration of the relative performance; complexity, and cost of the systems. Their major disadvantage is film fogging if stored in hot and/or humid environments for over a few months.

(b). Thermoluminescent dosimeters

These dosimeters have recently received the most research and devclopment attenliul in the fleld of personnel dosimetry. They offer some clear advantages over film dosimeters but also lack some of the performance features of film dosimeters. Perhaps the clearest and best defined advantage of these dosimeters is their ability to store radiation dose information over periods of many months under widely varying environmental conditions of temperature and humidity. It is doubtful that one would choose a film dosimeter for periods exceeding about one month in high-humidity, hightemperature areas. The thermoluminescent dosimeters (TLD) should perform well in these areas over time periods of at least one year. 
For emergency use on an intermittent frequency the long term storage properties of TLD bargain Eor their use. :

The distinct disadvantage in many of the early thermoluminescent dosimetry systems was the lack of attention to separating beta dose from photon dose during dosimeter evaluation. In monitoring mixed radiation fields, special attention to the design of dosimeters to provide this capability is required. Also, if appreciable doses of relatively low-energy photon radiation are to be received, film dosimeters, with their multi-filter system, provide the opportunity to evaluate the fraction of the total dose that may be of relatively Low energy and hence not so effective as the more penetrating higher energy radiations in delivering dose to the critical organs. Thermoluminescent dosimeters of special design are required to provide this same capability.

(c) Radiophotoluminescent dosimeters

Radiation-sensitive glass dosireters may be compared with film dosimeters essentially on the same basis as the thermoluminescent dosimeters. The principal advantage of the glass dosimetry systems is their ability to be reread repeatedly without altering or destroy-ing the dosimeter dose storage capabilities. This feature also permits their use as long-term integrating dosimeters with individual dose evaluation at any time throughout the period without intertering with the longer term dose integration. The principal disadvantages of the glass systems are the difficulties of separating low-energy photon and beta radiation from the more penetrating photor radiation and the care which needs to be exercised to avoid physical 
damage to the glass during its use and evaluation. A single chip on the corner of a glass block or a small grease or dirt stain on a glass aosimeter component can lead to a false evaluation. The new radiophotoluminescent systems are designed to minimize and attempt to avoid these difficulties.

(d) : Condenser ionization chamber dosimeters

Condenser ionization chambers have long been used to provide short-term dosimetry information for radiation workers. These dosimeters, also, known as 'pencil' and 'pocket chambers,' are highly developed. They may be obtained in dose ranges covering almost any area of conceivable interest. For most needs, the range from zero to $200 \mathrm{mR}$ is a commonly used dose range. For extreme emergency rescue operations, the range from zero to $600 \mathrm{R}$ may be required. The use of optical systems within these dosimeters permits the dose to be evaluated at any time by merely looking through the device. Hence, an on-the-spot dose estimate is possible. These devices are an effective and valuable dosimetry tool in the daily estimation of penetrating radiation accumulation. They find many applications in the daily control of radiation dose while performing. Emergency work or recovery operations. They are highly recommended for emergency response teams. 


\subsubsection{Neutron dosimeters}

The most commonly used personnel neutron dosimeters utilize a nuclear track film for fast-neutron detection. The film is evaluated by microscopically counting the photon recoil tracks that are developed in the processed silver bromide emulsion. Difficulties in utilizing dosimeters of this type arise primarily from the inability of the dosimeter to record neutron particles with energies less than $0.5 \mathrm{MeV}$ and from the time and effort required to examine the film microscopically at 400 to 900 power. Also, the tracks in the film have poor stability and track fading can become a problem if the film is used in environments of high temperature and humidity. Thermalnelutron dosimetry is accomplished with beta-ga!na dosimetry film and a two-filter system which provides one filter with a high thermal-neutron cross-section and a short activation product halflife and one filter with a low thermal-neutron cross section. The decay of the activation products created in the high cross-section filter will lead to darkening of the beta-gamma film behind this filter and the resulting difference in the film density measured behind the two filters can be calibrated to yield an estimate of the thermal-neutron dose.

Some applications for thermoluminescent materials for both thermal-and fast-neutron dosimetry are being made. Use of TLD noutron dosimelers seells advisable in view of their long storage propertics. It appeais duubtful that N'A tilms could be used conveniently for emergency infrequent use programs. Fission fragment track recording mica and plastics is also being sturied. No wholly adcquate personnel neulron dosimetry is 
currently available, but the TLD system using albedo neutrons seem to be the best.

\subsection{Ground and Road Surveys}

Special instrumentation can be designed for use on vehicles to provide a rapid survey of large ground areas and roadways. Although GM Tube instrumentation has been used, scintillation crystals are recommended for this purpose. Reasonably large (4".to 6" or even larger) scintillation crystals can be mounted near the ground in a protected assembly on the front of the vehicle with instrumentation, including recorder readout provided in the cab.. Traverse speeds of 5 to 15 miles per hour can be used with good results for most gamma emitters with energies of a few tenths. of a MeV or greater.

\subsection{Aerial Survey}

To survey. large potentially contamination areas, aerial survey techniques are highly effective. Large scintillation crystals up to 10 inches in diameter with multichannel analyzer systems can give some information relative to gamma ray energies and the quantities of radioactive materials on the ground. Survey heights of 500 feet or slightly less are commonly used. Aerial survey techniques are effective in giving an early scan of contamination areas and to determine the direction of contamination travel. Normally such information will need to be supplemented by surface surveys. Aerial survey equipment can be stored in a reasonably portable form, battery powered, and can be positioned for suitable performance in most light aircraft without modification. One need only provide occasional practice sessions to 
assure the equipment is operating and the staff is familiar with its use and interpretation. Good calibration is, of course, necessary, if other than wholly qualitative radioactive levels are to be determined.

\subsection{Special Sampling Equipment}

Special sampling equipment should be available to collect air, water, food, milk and similar samples at any area where radioactive materials are inadvertently released to the environs. Normally battery powered equipment is required for air sampling collection while simply defining sampling procedures and providing containers is usually adequate for the other sampling. Normally all samples will be taken to a laboratory for analyses. Some have elected to provide fully instrumented trailers or similar vehicles which can provide all of the support analytical capabilities for these samples in the field near the site of the emergency action. Each group will need to assess potential needs and priorities for this type of sampling capability. General criteria for some of the fixed station sampling of this type for use at reactor facilities is summarized in Appendix A.

\subsection{Selection criteria}

In selecting emergency instruments, the best instrument performance should be compared against the required performance factors. The multiple use needs for emergency situationis should be remembered in making the selection. The cost, maintenanre, calibration and durability of the instruments in emergency field use are other important criteria to be considered. Each instrument user will need to determine the relative importance of each 
performance criteria. Some typical requirements and performance ranges are reviewed for consideration.

3.6.1. Mechanical

(a) Structural strength

Instrumentation should be rugged enough to withstand typical field use. This might require construction in all-metal boxes with shockproof. component mounting capable of withstanding a drop test of one metre. In most cases the instrumentation will receive careful handling, and extremes in structural strength may not always be required. Ruggedly constructed readout meters are generally recommended, since the readout meter is one of the more shocksensitive instrument components.

(b) Component layout

All components of the instrument should be arranged so that they can be quickly replaced or repaired, and their performance checked and evaluated. Instrumentation design should avoid potential short circuits due to wear and tear. To avoid misinterpretation of instrument readings, human engineering features should be provided by clearly identifying instrument scales, readout adjustment controls and special performance features.

(c) Moisture and water resistance Instrumentation should be designed with sufficient moisture and water resistance to meet the needs of emergency use. This may be accomplished by using rubber gaskets and seals about control knob shafts and case fittings. 
(d) Safety features

Obvious safety features should be incorporated into the jnstrument design. No sharp corners or sharp and rough edges should be permitted. Sharp protrusions should be avoided. The design should avoid electrical shock hazards.

(e) Ease of handling

Special care. should be given in the design of the instrument to assuring ease in handling and reading. In many applications it may be necessary to use the instrument while wearing protective clothing, including heavy plastic gloves and perhaps a full face mask. This requires that the readout scales be large and easily readable and that the instrument controls be easily workable wilile wearing heavy gloves. The instrument should be comfortable to hold and use.

\section{(f) Ease of servicing}

Most emergency radiation monitoring instruments will be battery powered to provide maximum flexibility in use: provision should be made for quick and easy battery exchange. The electronics of the circuitry should be readily accessible so that necessary maintenance and circuit testing to locate malfunctioning components can be quickly completed. Care should be taken to provide adequate design so that instruments can be easily calibrated. The calibration adjustment potentiometers or other adjustable components should be positioned for easy access - but their positioning should not interfere with the normal use of the instrument. 


\subsubsection{Electrical}

(a) Power supply stability

The power supply should have sufficient stability to meet the calibration performance test and to avoid transients and fluctuations in the instrument readings:

(b) Battery life should provide for at least a hundred hours of continuous instrument use. If feasible, a battery-life indicator or a battery check point may be incorporated to evaluate the condition of the instrument batteries.

(c) Transient effects

No excessive transient effects should be noted. The instrument should give a steady reading and not fluctuate while in a uniform, non-varying radiation field.

(d) Switching transient

Switching transients should be avoided. When changing from one scale to another or when turning the instrument on, the readout meter should settle quickly to its stable reading. Switching transients should not exceed five seconds in duration.

(e) Capacitance and RF effects

Instrumentation should be designed and shielded so that meter readings are due only to the presence of ionizing radiation. The use of monitoring equipment near electric motors and electronic equipment should not produce superfluous or abnormal instrument readings. 
(f) Temperature dependence

The electronic circuitry and components should be designed and selected so that a stable and constant reading is obtained over the temperature range for which the instrument will be used. Normally, a temperature range near that required in the working environment will be adequate. Instrumentation should be tested and evaluated to determine its performance over a temperature range equalling that which might be encountered at any time in unsheltered field use of the instrument. Generally, tests over a range from the lowest to the highest temperature recorded for the region will be adequate.

(g) Geotropic effects

The instrument readings should not be affected by the orientation of the instrument with respect to gravity. In a uniform radiation field, meter readings should be constant for an instrument positioned in any orientation within the field.

(h) Extracameral radiation responses

All radiation responses should originate directly from the radiation effect on the instrument detector. Abnormal readings due to irradiation of the electronic circuitry or instrument components other than the deiector should not be observed. Careful scanning of the electronics of an instrument with a thin radiation beam of high intensity can be used to test for acceptable extracameral performance. Abnormal responses can usually be eliminated by providing electronic shielding or circuitry modifications. 


\section{(j) Linearity}

The instrument responses should normally be linear, or, if logarithmic scales are used, it should be strictly logarithmic. Calibration, or at least instrument evaluation at three points on each scale - high, mid-scale, and low - provides adequately for testing the linearity of response.

(k) Response time

Radiation monitoring instrumentation should have a fast response time to ensure good performance in non-uniform field monitoring. Experience has demonstrated that it is not difficult to design equipment which will rise to $90 \%$ of its ulitimate meter reading within seven seconds, and will fall to $90 \%$ of its final reading within seven seconds, after first exposure to or removal from a uniform radiation field.

\section{(1) Dependability}

Instrumentation should be dependable and ready to use within ten seconds after it is turned on. Emergency instrumentation will be used infrequently and performance should not deteriorate during periods of non-use.

\subsubsection{Radiological}

(a) Detection Iimit

The detection limit is the minimum radiation reading which can be obtained with the instrument. One should establish the needs for each particular type of instrumentation and application. For detection type instruments, 100 counts/min (at a counting geometry of a few per cent) from beta-gamma radiation spread over at least $100 \mathrm{~cm}^{2}$ should normally be detectable. For dose-rate 
monitoring. instrumentation, a detection limit of $1 \mathrm{mrem} / \mathrm{h}$ is usually adequate. However, lower detection limits, approaching $1.0 \mathrm{mrem} / \mathrm{h}$ may be desired.

\section{(b) Range}

The response range of the instrument is again a function of its potential use and the total instrument complement available. Betagamma detection instruments should have a response range from about 100 counts/min. to about 100,000 counts/min. Alpha detection instrumentation should have a range from about $500 \mathrm{dis} / \mathrm{min}$. to about $500,000 \mathrm{dis} / \mathrm{min}$. Commonly used dose-rate monitoring instruments should have a range from less than $1 \mathrm{mrem} / \mathrm{hr}$ to about $5,000 \mathrm{mrem} / \mathrm{h}$. Some emergency monitoring instruments with ranges to 5,000 or 10,000 $\mathrm{rad} / \mathrm{h}$ should be available.

\section{(c) Sensitivity}

The sensitivity of the instrument should be adequate to meet the monitoring needs. One should use large instrument readout scales and provide sufficient range switching so that good radiation dose control procedures can be practiced.

\section{(d) Accuracy}

Rigid calibration procedures to provide good accuracy in instrument performance are required and will be reviewed in detail in the section on calibrations.

\section{(e) Reproducibility}

Instruments should have good reproducibility and be capable of reproducing readings within $10 \%$ at any time in a given radiation field. 
(f) Saturation

All instruments shoula be driven off-scale at the high range of their measurement capability whenever they are positioned in radiation fields exceeding their maximum range. Extremely serious situations may arise if the instrument selected will not remain off-scale in very high radiation fields. If an instrument rises to a maximum of $75 \%$ of its top range and then remains constant or nearly constant in reading as the radiation fields increase, serious personnel over-exposures may result from abnormal radiation occurrences.

(g) Input voltage dependence

As far as possible, instrumentation should be designed so that. if the batteries weaken, instrument readings tend to increase.

(h) Energy ảependence

Energy dependence is an important consideration and should be well known. If correction factors are needed for energy dependence, they should be determined and readily available for use. Generally it is possible to select instrumentation with a low energy dependence for most of its intended applications.

(i) Temperature dependence

The effect of temperature on the radiation detector and possible corrections for this effect should be determined and used when necessary. Normally, for most field radiation monitoring situations, temperature effects will be negligible. A temperature correction may be required for the establishment of accurate calibration procedures. 
(j) Pressure dependence

The effect of atmospheric pressure on the radiation detector should also be determined and correction factors should be available for use if necessary. Normally this factor will not be required for typical radiation monitoring programs. A pressure correction may be required for the establishment of accurate calibration procedures.

(k) Angular dependence

The instrument should have minimum angular dependence. Experience has shown that angular dependence of $\pm 20 \%$ in the forward $2 \pi$ direction is generally available for most well designed monitoring instruments.

\section{(1) Stability}

The instrument should maintain a stable reading over periods of its use and should not drift appreciably once the zero point has been set.

(m) Responses to unwanted radiations

The instrument should not respond to radiations for which it is not calibrated or designed to measure. For example, neutron radiation monitoring instruments should not be affected by photon radiation fields up to $5 \mathrm{R} / \mathrm{h}$. Conversely, photon monitoring instruments should not be affected by neutron fields up to $5 \mathrm{rem} / \mathrm{h}$. 


\section{CALIBRATIONS}

\subsection{Purpose}

Al1. radiation instruments should be adequately calibrated so that their readings may be properly interpreted. The detailed calibration procedures to be used depend upon the types of instrument available and their use in the field. The frequency of calibration is also a function of the type of instrument and its use. Normally, detection type instruments should be calibrated when batteries are replaced or when maintenance and repair work is performed. A small check source should be used to verify that the instrument is responding prior to each use.

Dose-rate monitoring instruments should be recalibrated whenever they receive replacement batteries or maintenance: Prior to each field use of a dose-rate monitoring instrument, a quick check should be performed to ensure that it is functioning properly. This may be accomplished by exposing the detector to a small intense radiation source and noting the approximate meter position. Such checks are invaluable in detecting instrument malfunctions or total failures and may avert unnecessary radiation exposure to personnel due to the use of faulty instrumentation.

\subsection{Calibration Standards}

A number of calibration standards may be used for calibrating radiation instruments. The more commonly used standards are calibrated radionuclide sources, secondary instruments, free air ionization 
chambers, precision long counters, calorimeters and chemical dosimeters. Calibrated sources are easily used and maintained. Some nationally recognized group should provide primary calibrations to assure consistency for all radiation calibrations.

Cobalt-60, caesium-137 and radium sources may be calibrated with an accuracy of a few percent or better. These sources may then be used in low-scatter radiation positions to calibrate other sources or instruments. Primary calibrations may be provided with specially designed condenser ionization chambers, commonly known as $\mathrm{R}$ meters, or any of several similar systems now commercially available. Normaliy these standardizing instruments are calibrated against some primary source prior to their actual use. They offer many advantages to a calibration laboratory because they are small and convenient to use in establishing dose rates at locations within the calibration facility. Laboratory jigs, such as radiation source wells, may be calibrated with these instruments and subsequently the source wells may be used in the routine monitoring instrument calibration program. For energies below about $100 \mathrm{keV}$, a simple free air ionization chamber or sperially calibrated. $\mathrm{R}$ meter may be used for primary calibrations. The fundamental electrical measurements and the physical dimensions of the free air ionization chamber provide data for direct calculation of the radiation dose. For calibration of low-energy $x$-rays, this instrument is highly recommended.

A precision long counter or manganese sulphate bath provides a neutron moderating assembly for the accurate calibration of neutron flux. Calorimetry is a straightforward and fundamental method for calibrating all types of radiation sources - photon, beta and neutron. 
Calorimeters are normally not simple devices and are used primarily as precision control instruments for laboratory type measurements and fundamental calibrations.

\subsection{Calibration Equipment and Methods}

\subsubsection{Photon Calibrations}

For photon calibrations three types of radiation source are commonly used - radionuclides, filtered X-rays and $\mathrm{K}$-fluorescent $\mathrm{x}$-rays. Radiation sources may be used in scatter-free conditions for direct exposure of monitoring instruments or dosimeters, or in source wells or special jigs which have themselves been calibrated with appropriate secondary standards. Source wells permit the positioning of a radiation source vertically within a long, properly shielded tube, and are frequently used when many instruments of the same design require repeated calibrations. Collimated beams with or without special shielding are similarly used.

Heavily filtered $x$-rays may be used to provide calibrations at specific effective energies. These beams are normally calibrated with standard conderser ionization chamhers ( $R$ meters).

$\mathrm{K}$-fluorescent $\mathrm{X}$-rays may be used to provide energy response studies in the region of $8 \mathrm{keV}$ to $100 \mathrm{keV}$ and are usually calibrated with free air ionization chambers or $R$ meters. Special jigs and calibration equipment may be designed to position monitoring instruments or dosimeters about the filtered $\mathrm{X}$-rays and $\mathrm{K}$-fluorescent sources. 


\subsubsection{Beta-Particle Calibrations}

Beta-particle calibrations are usually provided by means of radioactive sources or, less frequently, by accelerators. Sources commonly used are strontium-90 and natural uranium in equilibrium with its daughters. Considerable discussion has centered on the surface dose rate of equilibrium uranium, but a value of $225 \mathrm{mili}$ $\mathrm{rad} / \mathrm{h}$ is generally accepted for a well-aged and smoothly polished natural uranium surface. Fundamental extrapolation chamber measurement may be performed to verify the surface dose rate of each slab of uranium used for calibration purposes. In providing beta calibrations, the geometry of the exposures may become an important factor in the use and interpretation of the instruments. If beta calibrations are provided from point sources, correction factors for proper interpretations will clearly be required when the instruments are used to monitor large area beta sources at short distances.

\subsubsection{Alpha-Particle Calibrations}

Most alpha-particle calibrations are provided by using radionuclide sources. Plutonium, uranium, polonium and other alpha emitters are used as sildil area sources, not point sources, for the calibration of detection type instrumentation. Alpha-particle calibrations and interpretations are usually not difficult because most energies are in the 4-5 MeV range and the calibrations can easily simulate the energies and geometries to be monitored in the field. 


\subsubsection{Neutron Calibrations}

Neutron calibrations may be accomplished with both isotopic neutron sources and neutron generating equipment. Frequently used neutron sources include radium beryllium, polonium beryllium, americium beryllium, plutonium beryllium, antimony beryllium ànd occasionally plutonium fluoride. These sources produce a broad spectrum of neutron energies, but generally give rise to relatively Low dose rates so that high dose-rate monitoring equipment cannot be calibrated by this approach. Neutrons from accelerator targets are usually required for dose rates greater than a few rem per hour. The accelerator target neutrons may be generated by small Van de Graaff accelerators.

\subsubsection{High-energy Photon and Particle Calibrations}

These calibrations require very special equipment and are usually performed in the field with the radiations to be monitored. Usually these radiations will be the result of high-energy physics experiments or other operations involving high-energy accelerators. Direct calibrations with calibrated tissue-equivalent chambers or with calorimeters are generally required. 


\subsection{Calibration Quality Control}

Any calibration facility will require a well organized and detailed internal quality control program. This program should provide a system of checks on all calibration jigs and assemblies and a schedule of recalibrations to assure top-quality control in the calibration operations: The use of monitoring instrumentation to signal abnormal conditions should be a fundamental part of each calibration jig.assembly. Of equal importance is the training and assignment of fully qualified staff to the calibration function. One should select individuals who clearly possess traits of good organization and attention to detail. A cajibration facility should not be operated by an inexperienced staff in training for other radiation protection assignments, although it can provide good training and background for staff members assigned to assist in the calibration functions. Trainees should always be under the supervision of an experienced and competently trained calibration staff member.

\subsection{Required Calibration Accuracies}

Calibratiun accuracics may be identifed at five levels of performance: primary standards, secondary standards, laboratory standards, field standards and emergency standards. Primary standards are those established within a country or group of countries and utilized to assure consistency in interpretation and measurement of radiation quantities. Secondary standards are those standards utilized by the individual laboratories in providing their calibrations of field 
instrumentation and laboratory special-studies equipment. Laboratory standards are those standards utilized in precision radiochemistry and physics work. They generally incorporate precise instruments under environmental controls not normally availeble in radiation monitoring and dosimetry in the field. Field standards indicate the degree of performance that is required and that can be obtained in routine field radiation protection programs. Typical standards for photon, beta, and neutron radiations for each of these four calibration categories are summarized in Table II. TABLE II. SUGGESTED RADIOLOGICAL STANDARDS

\begin{tabular}{llll}
\hline Standard Category & $\begin{array}{c}\text { Radiation } \\
\text { Type }\end{array}$ & $\begin{array}{l}\text { Radiation } \\
\text { Quantity }\end{array}$ & $\begin{array}{l}\text { Allowable } \\
\text { Error }(\%)\end{array}$ \\
\hline I. Primary & All & All & State of the Art \\
II. Secondary & Photon & Exposure & \pm 2 \\
& Beta & Dose & \pm 5 \\
& Neutron & Dose & \pm 5 \\
III. Laboratory & Photon & Exposure & \pm 5 \\
& Beta & Dose & \pm 10 \\
& Neutron & Dose & \pm 10 \\
IV. Operational Radiation & Photon & Exposure & \pm 20 \\
Protection & Beta & Dose & \pm 25 \\
& Neutron & Dose & \pm 25 \\
V. Emergency & Photon & Exposure & \pm 40 \\
& Beta & Dose & \pm 40 \\
& Neutron & Dose & \pm 40
\end{tabular}




\section{RADIOLOGICAL INSTRUMENTATION INTERPRETATIONS}

\subsection{Objectives of Instrumentation Design}

Radiation instrumentation should be designed to meet the needs of emergency radiation monitoring, and to minimize interpretation requirements. Instrumentation which gives accurate responses over a wide range of radiation energies and geometry situations should be selected and used wherever possible. Supporting instrumentation to provide special-studies capabilities in the field and to define actual or potential instrument errors can be used for an experimental determination of necessary correction factors and instrument interpretation. By designing calibration facilities to duplicate anticipated emergency field conditions, many difficult interpretation problems may be avoided.

\subsection{Correction Factors}

\subsubsection{Energy}

Ionization chamber dose-rate monitoring instruments are generally energy dependent over a wide range of energies and will require correction only when very high energies or very low energies are encountered. At energies beyond about $5 \mathrm{MeV}$, where pair production becomes the primary energy dissipation process, corrections will be required. At low energies below about $50 \mathrm{keV}$, where absorption in the chamber walls may become an important factor, specially designed instruments should be used or correction fartors should be applied. Most emergency applications will not involve these applications. Neutron monitoring instrumentation may be extremely sensitive to neutron-energy spectrum changes, and, hence, may require a good 
measurement of the neutron spectrum for instrument readout interpretation.

For personnel film dosimeters the use of multi-filter systems will permit simultaneous evaluation of photon radiation in the range between $50 \mathrm{keV}$ and $3 \mathrm{MeV}$, photon radiation in the range between 10 and $50 \mathrm{keV}$ and beta radiation in the range from $0125 \mathrm{MeV}$ to 3 MeV. Low-energy photon radiation is determined by noting the density difference on developed film areas behind two filter materials having an approximately equal electron density but different atomic number. The high absorption coefficient for the high atomic number material will substantially shield low-energy photons from that area of the film, resulting in a filter density difference that can be calibrated to yield an evaluation of the incident low-energy photon dose.

Beta radiation dosimetry may be obtained from the readout difference from detectors behind an 'open window' or low-mass filter area and a plastic filter area. Some readout difference between these detectors may arise from the low-energy photon radiation present, but a correction may be made for this contribution once., the low-energy photon dose is determined from two other filters. A highenergy gamma dose may be read directly from the detector behind a thick metal filter of nearly one gram per square centimetre. The thick filter is recommended to prevent misinterpretation of beta radiation as photon radiation. The determination of gamma radiation above $5 \mathrm{MeV}$ with personnel dosimeters will require a special calibration and probably cannot be accomplished in the presence of other radiation types unless rather extensive multi-filter dosimeters are used. TLD systems usually use only one or two detectors 
for simple dosimetry purposes although systems with up to Eive detectors are in use when neutron dose is also to be determined.

\subsubsection{Geometry}

For most penetrating photon radiation, geometry corrections will not be required because chamber walls and instrument design are readily available to meet typical geometrical considerations. For beta radiation, geometry corrections may be necessary. The effect of calibrating with point sources and then measuring broad area sources in the field will require correction factors. When distances of two meters or less are involved. At greater distances correction factors are usually not of importance for emergency radiation monitoring applications. One may determine the correction factors experimentally or may calibrate instrumentation with broad sources to meet most broad field emergency monitoring requirements.

A similar situation is encountered in the calibration of personnel dosimeters. One may determine experimentally the magnitude of this effect for the dosimeter design and beta calibration sources. These experiments should be performed when the dosimetry program is first established and the appropriate correction factors applied in the interpretation of the results or incorporated directly in the calibration procedure.

Neutron dosimetry problems require geometry corrections only when large moderators or scattering devices are located near the detector. One should attempt to complete neutron monitoring measurements and calibrations under conditions paralieling those encountered in the field. One should not stand too close to a 
neutron monitoring instrument while making a reading. Nétron moderation and scattering by the human body can significantly alter the instrument reading.

\subsubsection{Mixed Radiation Fields}

Instrumentation should be designed to minimize the effects of mixed radiation fields. Tissue-equivalent chambers and tissue-like chambers may be used to separate photon and neutron components and to permit appropriate dose interpretations under some monitoring conditions. Normally monitoring and dosimetry instrumentation for photons, beta particles and neutrons can be designed to avoid the necessity of making these corrections.

\subsubsection{Environmental Factors}

Corrections for the environmental factors of temperature, pressure and humidity are the most common ones encountered. The accuracies required for most emergency radiation monitoring situations will not require corrections for these factors. For precision measurements of great accuracy, such as required in the establishment of dose rates within a calibration facility, standard temperature and pressure corrections should be made. Hunidity corrcctions are best made by special calibrations and studies to determine their contributions. In personnel dosimetry, high temperature and high humidity may substantially affect storage properties of the dosimeters, and some correction factors may be required. These are usually best determined by exposing calibration dosimeters to conditions identical to those encountered in the field and by using the calibrated dosimeters directly in interpreting field dosimeters. 
\begin{tabular}{l|l} 
This technique provides adequate environmental factor correction \\
without specific calculation of the correct factors.
\end{tabular}

\section{EMERGENCY KITS}

An important part of being able to cope promptly and effectively with any emergency radiation situation is having available all necessary equipment as well as thoroughly thought-out emergency plans. Assembly of emergency equipment into emergency kits is highly recommended for assuring the availability of critical needs. Emergency kits should be limited in size to that which can be easily handled by two individuals and, preferably for a single person. The kits need only contain those items of equipment that will be needed during the initial first few hours at the site of the emergency. Additional and supporting equipment can always be brought in at a later time. The critical part of a good emergency kit is a kit seal that will assure the kit has not been opened prior to its use and that all components are in fact available within the kit. It is suggested that wire seal devices be used to insure kit integrity and that a clearly defined and responsible staff check over the contents of each kit whenever a seal is broken. 'l'he actual contents of each kit need to be determined by considering the potential accidents and uses that may be encountered. A suggested list of useful items is shown in Table TII. 
TABLE III

\section{EMERGENCY KIT CONTENTS}

Emergency Monitoring Instruments

High Range Dose Rate Instruments

Self-Reading Pocket Dosimeters and Chargers

$$
\begin{aligned}
& 0-200 \mathrm{mR} \\
& 0-1 \mathrm{R} \\
& 0-10 \mathrm{R} \\
& 0-50 \mathrm{R} \\
& 0-600 \mathrm{R}
\end{aligned}
$$

Instructions for Emergency Site Monitoring and Control

Assault Masks

Credit Cards

Coveralls

Cash

Gloves

Hoods

Canvas Boots

Rubber Shoes

Maps

Masking Tape

Flashlight (extra batteries)

Plastic Bags

Stop Watch

Date Book

scotch Tape

Slide Rule

Scissors

Radiation Zone Signs

Keep-Out Signs

Small Diameter Rope

Bound Writing Pad and Pencils

Camera (with flash bulbs) 
Table II (continued)

Radiation Check Sources

Whistle

Compass

Tape Recorder

List of location of all emergency kits

Personnel Questionnaire Record Cards

Fersonnel survey Record Cards

Area survey Record Cards

List of critical telephone numbers

Sampling containers for soil and water samples

Emergency Plan

Personnel decontamination supplies 


\section{SUMMARY}

Emergency radiation monitoring instruments should be selected to meet the specific needs of each emergency program. Proper instrumentation selection and calibration can simplify measurement interpretations. Many interpretation factors can be designed within the calibration programs to result in instrumentation readout that will not require correction factors for measurement interpretation. The degree of instrumentation interpreation and measurement corrections required is a function of the intended use of the information. It requires maximum attention for primary calibration measurements and minimum attention for most emergency radiation measurements.

A special study, recently completed, has defined emergency instrumentation performance requirements for power reactors. The requirements for emergency radiological instrumentation that would be suitable for use away from the reactor facility itself is given in Appendix A. This material is abstracted from BNWL-1635, "Technological Considerations in Emergency Instrumentation Preparedness - Phase II-A - Emergency Radiological and Meteorological Instrumentation Criteria for Reactors," prepared under the direction, of J.M. Selby of Battelle-Northwest. 
APPENDIX A

Abstracted from BNWL-1635

\section{EMERGENCY INSTRUMENTATION CRITERIA}

The Emergency Instrumentation Criteria presented in this section are primarily performance criteria. Specific instrument systems, components or individual instruments which should meet these criteria are discussed in Sections IV and V. Throughout these criteria four verbs have been used to indicate the degree of rigor intended by the specific criterion. "Shall" and "Will" indicate that strict application of the criterion is possible and is considered necessary to assure the instrumentation or systems will perform as needed during an emergency. "Should or "Would" indicate that the application of the criterion is desirable.

Some of the radiological and environmental criteria are severe and calibration or certification are beyond the capability of individual nuclear facilities. Therefore, it is important that these instruments, systems or individual components be thoroughiy tested at least once under all extreme conditions of operation to assure conformance with the criteria.

VI.A. RADIOLOGICAL INSTRUMENTATION SYSTEMS

VI.A.l. General Criteria for Installed Radiological Systems

1. The system shall have an internal electronic calibration check, which shall check operation of all circuitry other than the detector.

2. The system shall be fail-safe; in the event of a malfunction or failure, an internal audit circuit shall be activated and transmit an appropriate signal to a central manned location.

3. The system shall be capable of opcration on $117 \mathrm{~V} \mathrm{f0} \mathrm{Hz} \mathrm{AC}$, and shall be unaffected by voltage or frequency changes of $\pm 20 \%$. Emergency power capability shall be included in the design and installation, and shall be automatically implemented when required, with no more than a six second delay. 
4. When responding to levels in excess of the maximum specified range, the instrument should not paralyze and the readout signal shall remain full upscale.

5. Switches and other controls shall be protected to prevent inadvertent deactivation or operation of system.

6. Overall. system accuracy sha 11 be $\pm 40 \%$ at the $95 \%$ confidence level over the entire operating range, with precision $\pm 10 \%$ for any single measurement level.

7. Overall system response time from 0 to $90 \%$ of full reading shall be $\leq 2$ seconds.

8. There shall be no deleterious effect to the system from radiofrequency and microwave exposure to $10 \mathrm{~mW} / \mathrm{cm}^{2}$, photon exposure to $5 \times 10^{5} \mathrm{R}$, referenced to the energy range between $0.8-1.2 \mathrm{MeV}$, and from electrostatic charges with potentials to 10,000 volts.

9. The operating temperature range of the system shall encompass the extremes anticipated. Where the instrumentation may be exposed directly lo ambient outside temperatures, the 50 year extremes shall be applied.

10. For the operating temperature range the temperature coefficient sha 11 he $\leq 0.5 \%$ per ${ }^{\circ} \mathrm{C}$ and it should be $\pm 15 \%$ over the entire range.

11. The instrument system shall be unaffected by relative humidities from $5 \%$ to $95 \%$ over the designated temperature range.

12. The system shall be able to withstand mechanical stress equivalent to a peak overpressure of $15 \mathrm{psi}$. If located within the containment tacility, the system shall be able lu withstand mechanical stress equivalent to a peak overpressure of $50 \mathrm{psi}$. 
13. Logarithmic or digital readout should be employed.' If multiple ranges are used, automatic range changing shall be provided. Manual adjustment of range shall be unnecessary.

14. Readout capability shall be provided in the control room and at least two other physically separate locations, one of which shall be the emergency operations center, and the other at or near the detector.

15. All units of similar function, including detectors, electronic modules, readout and display devices and power supplies, shall be wholly interchangeable within type.

16. Except as noted, the electronics shall meet the specifications for and be compatible with the AEC standard nuclear instrument modules, (67) thus ensuring a basic standard, ease of maintenance, and providing interchangeability and compatibility.

17. Electronic and other supporting components should reflect the latest technology with solid state (i.e., transistorized) circuitry incorporated throughout, as practicable. The use of integrated circuits should be considered.

18. All modules shall be accessible for test without removal from the circuit. Plug-in type units should be considered.

19. The instrument system shall be equipped with an alarm capable of being externally set to alarm at any point over the stated range. The alarm should be both audible and visible, and should be capable of reset without removing the instrument from service. 
VI.A.2. General Criteria for Gaseous and Particulate Sampling

1. The system shall be designed to remove on a continuous basis, a representative sample.

2. The location for sampling should be close to the point of release.

3. Particulate-generating gas phase reactions, corrosion, or release of contaminants, should be absent downstream of the sampling point.

4. When sampling a stack, the sampling point shall be no less than five dur.t diameters and preferabiy should be at least 10 duct diameters downstream from any injection point or point of turbulence or transition. A multi-entry probe shall be used for sampling in the duct or stack.

5. Sampling conditions should approach isokinetic. The inlet velocity to duct velocity should be $1.0 \pm 0.2$.

6. Sampling lines shall be kept short. The distance from sample point to collector should be less than 10 feet. Sample line bend radii shall exceed five sampling line diameters.

7. The sample delivery system shall be corrosion resistant and designed for streamline flow with no right angles or sharp bends. Stainless steel should be used for construction and plate out of radioactive material should be less than $5 \%$.

8. A constant sample flow rate shall be used and a constant displacement pump should be used as the air mover. An appropriately calibrated airflow meter shall continuously verify flow rate, and shall be accurate to within $\pm 20 \%$. 
9. Particulate radioactive material shall be removed by membrane filters with pore size $\leq 5 \mathrm{um}$, having an efficiency of $\geq 99.5 \%$ for particles with diameters $\geq 0.3 \mu \mathrm{m}$.

10. Charcoal impregnated with potassium iodide shall be used to sample airborne radioiodines. A minimum of $99.5 \%$ removal shall be required with a minimum 24 hour retention at the maximum concentrations expected. The charcoal medium should follow the particulate filter in the same sample stream. 
VI.A.3.e. Criteria for Environmental Air Monitor

The criteria listed below are in addition to those general criteria presented in Sections VI.A.I and VI.A.2.

1. The system shall be designed to take on a continuous basis a representative sample of the ambient air. The preferred sampling location is at one meter above ground level, in a location free from unusual micrometeorological or other conditions (e.g., proximity of large buildings, vehicular traffic) which could result in artificially high or low air concentrations.

2. Direct sampling with no lines upstream of the sample medium is greatly preferred.

3. The sample collector shall be easily readable in place with portable monitoring instruments and removable for subsequent laboratory analysis.

4. The measurement capability for particulate activity shall have a minimum range of $10^{-6}$ to $10^{-1} \mathrm{Ci} / \mathrm{cm}^{3}$ gross beta referenced to ${ }^{90} \mathrm{Sr}-\mathrm{Y}$. This range shall overlap the range of instrumentation used for routine or nonemergency monitoring.

5. For radioiodines, the measurement capability shall be $10^{-7}$ to $10^{-2}$ $\mathrm{Ci} / \mathrm{cm}^{3}$ referenced to ${ }^{131}$ I. This range shall overlap the range of routine or nonemergency instrumentation used for monitoring radiojodine in the environs.

6. The instrument system shall be protected from the external environment, and shall be housed in a locked facility to afford a measure of security from accidental or willful damage or tampering.

7. The entire system operation shall be checked at least quarterly and calibrated and maintained when indicated.

\section{VI.A.3.f. Criteria for Liquid Effluent Monitor}

The criteria listed below are in addition to those general criteria presented in Section VI.A.I.

1. The detector system should consist of a small (typically an $0.5 \mathrm{x}$ 0.5 in. right cylindrical) $\mathrm{NaI}(\mathrm{TI})$ crystal.

2. The detector and photomultiplier shall be optically coupled and hermetically sealed into an integral container. 
3. The minimum thickness of the material around the detector shall be at least $400 \mathrm{mg} / \mathrm{cm}^{2}$; preferred thickness is $1000 \mathrm{mg} / \mathrm{cm}^{2}$.

4. The detector resolution shall be $\pm 12 \%$ FWHM for the $1.17 \mathrm{MeV}$ photon peak associated with ${ }^{60}$ Co decay.

5. The photomultiplier tube shall be provided with mu metal or other shielding to obviate the effects of magnetic fields.

6. The detector shall be capable of operating completely submerged.

7. The system shall be capable of detecting gross radioactivity in aqueous liquids over the range $10^{-9}$ to $10^{-4} \mathrm{Ci} / \mathrm{cm}^{3}$, referenced to photons with energies greater than $0.6 \mathrm{MeV}$, and assuming 0.5 photons per disintegrations.

8. If the system is used to monitor a liquid stream, a flow meter, accurate to within $\pm 20 \%$, shall be provided. This flow meter should also have remote readout capability; integrating capability. should be considered.

9. If the system is used to monitor a static or nearly static volume of liquid, provision shall be made to accurately monitor liquid volume, or alternatively, liquid level.

10. The photon peak at $1.17 \mathrm{MeV}$ from ${ }^{60} \mathrm{Co}$ shall be used to calibrate the system. The system shall be checked quarterly with a source and calibration and maintenance performed when indicated.

VI:A.3.g. Criteria for Ambient Radiation Monitoring Instrumentation The criteria listed below are in addition to those presented in Section VI.A.T.

1. The system shall be capable of detecting separately dose contribution from beta and low energy photon radiation, and the high energy photon radiation.

2. Photon energy dependence shall be $\pm 20 \%$ over the range $30 \mathrm{keV}$ to $3 \mathrm{MeV}$. 
3. Beta energy dependence shall be $\pm 30 \%$ over the range 0.1 to $3 \mathrm{MeV}$.

4. The system shall have an internal electronic calibration check and an internal radioactive check source for the detector. These shall be capable of remote operation, i.e., the check shall be capable of being made from the Emergency Control Center. Calibration and operating checks shall be made monthly and recalibration and repair accomplished when indicated. If integrating capability is provided, this feature shall be reset at the time of calibration check.

5. Detector placement shall be such that a representative measurement of the ambient field is obtained. The detector shall therefore be protected from fallout accumulations, shadow shielding, and similar effects. The recommended detector height is one neter above ground level in the environs.

6. If the ambient radiation monitor is to be used in the containment vessel the following shall apply:

- The detection range for photons shall be 1 to $10^{6} \mathrm{R} / \mathrm{hr}$.

- The detection range for beta radiation shall be 10 to $10^{6} \mathrm{rad} / \mathrm{hr}$.

- Extracameral response shall be undetectable in photon fields to $10^{6} \mathrm{R} / \mathrm{hr}$ referenced to $1 \mathrm{MeV}$ energy, beta fields providing an air dose rate of $10^{6} \mathrm{rad} / \mathrm{hr}$ referenced to $2 \mathrm{MeV}$, either singly or concomitantíy.

7. If the ambient radiation monitor is to be used in the reactor building or environs the following shall apply:

- The instrument system shall have a measurement range for photons of $10^{-3}$ to $10^{4} \mathrm{R} / \mathrm{hr}$. If an integration mode is provided, its operation should be simultaneous with the rate mode and 1 ts range shuuld be $10^{-2}$ to $10^{4} \mathrm{R}$.

- The measurement range for beta radiation shall be $10^{-2}$ to $10^{-4}$ $\mathrm{rad} / \mathrm{hr}$. If a simultaneous integration mode is provided, its range should be $10^{-2}$ to $10^{4}$ rad.

- Extracameral response shall be absent in photon fields to $10^{4} \mathrm{R} / \mathrm{hr}$ referenced to $1 \mathrm{MeV}$ energy, and beta fields providing an air dose rate of $10^{4} \mathrm{rad} / \mathrm{hr}$ referenced to $2 \mathrm{MeV} \mathrm{E}_{B}$ maximum either singly. or concurrently. 
VI.C. CRITERIA FOR AMBIENT RADIATION AND CONTAMINATION SURVEY INSTRUMENTS

VI.C.7. Dose Rate and Contamination Survey Instruments

1. The system shall be capable of detecting beta and photon radiation, and separating the contribution from each. To accomplish this, a detector system which can be operated bare or which can be shielded with $1 \mathrm{gm} / \mathrm{cm}^{2}$ of polyethylene or similar low $\mathrm{Z}$ plastic, should be used.

2. The detection ranges shall be as shown:
a. Photon Exposure Rate:
$0.1 \mathrm{mR} / \mathrm{hr}$ to $10^{4} \mathrm{R} / \mathrm{hr}$.
b. Beta Dose Rate:
$0.1 \mathrm{mrad} / \mathrm{hr}$ to $10^{4} \mathrm{rad} / \mathrm{hr}$.

In recognition of the difficulties in design and construction of a single detector and/or instrument with such a breadth or range, two detectors or instruments are permissible, assuming that all the other criteria specified in this section are met, and that a one decade overlap is provided.

3. Photon energy dependerice shall be $\pm 15 \%$ over the range $30 \mathrm{keV}$ to $3 \mathrm{MeV}$.

4. Detection capability shall be provided for beta particles with energies greater than $100 \mathrm{keV}$. The beta energy dependence shall be $\pm 30 \%$ over the range 0.1 to $3 \mathrm{MeV}$.

5. Detectors and associated electronic circuitry, readout and display devices, and power supplies shall be wholly interchangeable.

6. Overall system accuracy sha 11 be $\pm 40 \%$ at the $95 \%$ confidence level for any level over the entire operating range, with precision of $\pm 10 \%$ for any single measurement level.

7. Overall system response (0 to $90 \%$ of full reading) time shall be $\leq 2$ seconds after a warm-up time of one minute. This does not preclude the inclusion of variable response time capability. When the radiation field is removed, the instrument shall indicate within 2 seconds not more than $10 \%$ of the total reading in the field. 
8. Stability shall be evidenced by the ability of the instrument to maintain zeroing, accuracy, and precision. for at least 24 hours after initial switching on.

9. For the operating temperature range the temperature coefficient shall be $50.5 \%$ per ${ }^{\circ} \mathrm{C}$ and it should be $\pm 15 \%$ over the entire range.

10. The operating temperature range of the system shall encompass the extremes anticipated. Where the instrumentation may be exposed directly to ambient outside temperatures, the 50 year extreme shall be applied.

11. The instruments sha11 be splash-proofed. The instrument system shall be unaffected by relative humidities from 5 to $95 \%$ over the designated temperature range.

12. When responding to levels in excess of the maximum range, the readout shall remain full upscale.

13. Extracameral response should be undetectable in photon field to $10 \mathrm{R} / \mathrm{hr}$ referenced to $1 \mathrm{MeV}$ energy, and to beta fields providing an air dose of $10 \mathrm{rad} / \mathrm{hr}$ referenced to $2 \mathrm{MeV}$.

14. There shall be no deleterious effect to the instrument from radiofrequency and microwave exposure to $10 \mathrm{~mW} / \mathrm{cm}^{2}$, photon exposure to $5 \times 10^{5} \mathrm{R}$, referenced to the energy range between $0.05-1.2 \mathrm{MeV}$, and from electrostatic charges with potentials to 10,000 volts.

15. The system shall be unaffected by magnetic fields with intensity to 10 oersteds.

16. With the exception of the detector and display, solid state electronics should be used throughout.

17. The instrument shall be designed to be powered by $D$ cells or 9 volt transistor batteries meeting the specifications published by the U.S. National Bureau of Standards. (74) Compatibility with alkaline, Ni Cd, or mercury cells should be considered. Provision for operation from a standard automobile 12 volt system and 117 volt, $60 \mathrm{~Hz}$, alternating current also should be considered. 
18. Minimum battery lifetime shall be 200 hours of continuous duty operation at an exposure level of $10 \%$ the maximum full scale reading, at temperatures above $0^{\circ} \mathrm{C}$. At temperatures below $0^{\circ} \mathrm{C}$, alkaline batteries shall be used and the minimum battery lifetime shall be 100 hours of continuous operation.

19. Geotropism, or change in reading with special orientation, shall be $\leq 2 \%$ of full scale reading.

20. Response to noise and vibration shall be undetectable at sound pressure levels $\leq 100 \mathrm{db}$, and vibration frequencies of 10 to $100 \mathrm{~Hz}$, with a total excursion of $0.5 \mathrm{~mm}$.

21. Sensitivity shal 1 be $\leq 5 \%$ of mid-scale or decade, where sensitivity is defined as the minimum detectable change in response.

22. Angular dependence shall be $\leq \pm 15 \%$ in a $2 \pi$ steradian frontal direction, referenced to photons with energies in the region $1 \pm 0.2 \mathrm{MeV}$.

23. The instrument shall be equipped with a battery check switch and indicator of battery condition. Low or dead battery indication shall be positive - i.e., the instrument shall read upscale, and zeroing shall be rendered impossible.

24. Readout shall be direct and in units of dose or exposure per hour. However, high range instruments intended exclusively for rescue work may be calibrated in units of R/min or $\mathrm{rad} / \mathrm{min}$, and if so, the instrument and readout should be clearly and distinctively marked. The readout shall be such that multipliers (e.g., $\times 10, \times 100$ ) shall be included.

25. The readout shall be lighted to permit use in darkness; selfillumination should be considered.

26. The instruments, whether used routinely or not, shall be checked for operation on a quarterly basis, and recalibrated and repaired as indicated. In no case shall more than 18 months elapse between calibrations. 
27. Overall instrument response shall not change by more than $\pm 10 \%$ from the previous calibration when batteries are changed.

28. A $10 \mathrm{mV}$ or $\mathrm{mA}$ recorder output shall be provided for instruments which are to be used with a recorder.

29. The total weight of the fully assembled survey meter, including batteries, should not exceed $3 \mathrm{~kg}$ (6.6 ibs).

30. If the survey instrument is to be operated while carried (portable) the following shall apply:

- The instrument is capable of and designed for, convenient transportability by a single person. This criterion does not preclude the use of back packs, neck or shoulder straps, belts, or other means of attachment to the body

- The weight of the total instrument, including power source, does not exceed $22.5 \mathrm{~kg}$ (50 lbs).

31. If the survey instrument is to be operated while mounted in an airplane, motor vehicle or boat (mobile) the following shall apply:

- Any of the instrumentation that may be used in an airplane shall be designed to operate properly at an altitude of 5000 feet over the surrounding terrain.

- Mobile instrumentation shall be designed to provide a readout using a strip chart recorder.

- Each separate protion of the mobile instrument system shall weight less than 50 pounds.

32. If an integrating capability is provided the following shall apply:

- Portable radiological instruments with integrating capability should have integrating ranges as shown:
a. Photon Exposure
0.1 to $10^{3} \mathrm{R}$
b. Beta Dose
0.1 to $10^{3} \mathrm{rad}$ 
- Integrating units shall be equipped with an audibile alarm having a continuous or intermittent warbling tone with a frequency in the region 2 to $7 \mathrm{kHz}$ and a sound level of $85 \mathrm{dbA}$ at a distance of $50 \mathrm{~cm}$ from the instrument.

- The alarm shall be presettable to any level by an external switch. External reset capability shall also be provided.

- An alarm test position or switch shall be provided.

\section{VI.C.2. Portable Air Samplers}

1. The sampler shall be designed for use with the portable survey meter described in VI.C.

2. To simplify calibration, operation, and interpretation, a fixed sampling rate of 10-30 liters per minute should be used. Sampling rate sha 11 remain constant to within $\pm 25 \%$ during normal operation.

3. The unit shall be compatible with standard glass fiber, cellulose fiber, and charcoal loaded filters commonly used for air sampling. The size of the filter used is dependent upon the size of the detector, but a $47 \mathrm{~mm}$ diameter should be considered. Filter diameter should not exceed $100 \mathrm{~mm}$.

4. The filter material used shall have an efficiency of $99.5 \%$ for particles $0.3 \mu \mathrm{m}$ in diameter.

5. Power should be provided by wet cells, and these shall conform to the specifications put forth by the National Bureau of Standards.

6. Battery lifetime shall be greater than eight hours under load.

7. The sampling unit shall be provided with a battery test or other indicator of battery condition.

8. Air flow shall be continuously indicated by an appropriate clearly marked gage having an accuracy of $\pm 20 \%$. 
VI.C.3. Direct Reading Dosimeters

1. The pocket ion chamber shall have a range of 0 to $200 \mathrm{R}$ if it is to be used for personnel involved in rescue work in which exposures to $100 \mathrm{R}$ may be incurred. (71) If used for other purposes, such as protection of property, the range shall be appropriate to the maximum permitted exposure. The maximum permitted exposure shall be in the range of 40 to $70 \%$ of full scale of the pocket ionization chamber used.

2. The instrument shall be provided with an optical system to permit direct readout. Major scale divisions shall be indicated by heavy lines at 0,50 , and $100 \%$ of scale; the scale should be further subdivided into tenths and twentieths by progressively shorter and/or less bold lines.

3. Leakage shall be $\leq 2 \%$ of full scale in a 24 hour period.

4. Accuracy shall be $\pm 25 \%$ of the true exposure at the $95 \%$ confidence level, referenced to 20 to $80 \%$ of full scale exposure. Precision at any level shal1 be $\pm 10 \%$.

5. Energy dependence shall be $\pm 20 \%$ for photons in the energy range $35 \mathrm{keV}$ to 2 li.ev.

6. The instrument system shall be unaffected by relative humidities from $5 \%$ to $95 \%$, over the designated temperature range.

7. For the nnerating temperature range the temperature coefficient shall be $\pm 0.5 \%$ per ${ }^{\circ} \mathrm{C}$ and it should be. $\pm 15 \%$ over the entire range.

8. The unit shall be rate indpendent to $10^{6} \mathrm{R} / \mathrm{sec}$.

9. There shall be no deieterious effect to the dosimeter from radiofrequency and microwave exposure to $10 \mathrm{~mW} / \mathrm{cm}^{2}$, photon exposure to $5 \times 10^{5} \mathrm{R}$ referenced to the energy range between $0.05-1.2 \mathrm{MeV}$, and from electrostatic charges with potentials to 10,000 volts.

10. The unit shall be unaffected by magnetic fields with intensities of 10 oersteds. 
11. The unit shall be able to withstand mechanical stress or shock equivalent to a drop from a height of three feet onto a hard surface and such a shock or stress shall not change or alter any reading more than $\pm 10 \%$ of full scale.

12. Change in reading with spatial orientation shall be $\leq 2 \%$ of full scale.

13. Angular dependence shall be $\leq 15 \%$ over the energy range $35 \mathrm{keV}$ to $2 \mathrm{MeV}$.

14. Sensitivity shall be $s 5 \%$ of midscale.

15. The unit shall (1) be nonresponsive to beta radiations with energies $\leq 2 \mathrm{MeV}$, or (2) shall be accurate to within \pm 30 for beta radiations with energies from $100 \mathrm{keV}$ to $2 \mathrm{MeV}$. If the latter is selected, the scale shall be calibrated in rads, and for photons $1 \mathrm{R}$ can be taken to equal $1 \mathrm{rad}$.

VI.C.4. Personal Alarm Dosimeters

1. The criteria estab?ished for the integrating survey meters in Section VI.C.l. shall apply.

2. The personal alarm dosimeter shall have a range from 0 to $200 \mathrm{R}$.

3. A meter, digital register or other readout shall continually register the accumulated dose.

4. The instrument sha11 weigh no more than 425 grams $\left(\begin{array}{ll}8 & 0 z\end{array}\right)$.

5. The instrument should be powered by any single or combindlion of commercially available alkaline type dry cells. Mercury cells, while acceptable, are discouraged. 